\title{
Inter-Instrument Comparison of Bioimpedance Spectroscopic Analysers
}

\author{
L.C. Ward*
}

The University of Queensland, School of Chemistry and Molecular Biosciences, St. Lucia, Brisbane, Australia

\begin{abstract}
Three commercially available bioimpedance spectroscopy analysers were compared for technical performance and for their design purpose of prediction of body composition. All three analysers were electronically stable, remaining in calibration over a year, and provided highly reproducible (coefficients of variation $<0.5 \%$ ) and accurate (within $0.5 \%$ of component values) measurements of impedances of a test circuit. Whole body impedances in humans were highly correlated between all three instruments although significant biases between instruments were observed, particularly for the measurement of intracellular resistance. However, when the measured impedances, and using instrument-specific resistivity coefficients, were used to predict fat-free mass of the subjects, the difference between instruments was approximately $1.7 \mathrm{~kg}$ fat-free mass, a value comparable with that observed for the error associated with reference methods such as multi-compartment models of body composition. It is concluded that, with appropriate regard to standardisation of measurement protocol, all three analysers are suitable for their design purpose of estimating body composition in humans.
\end{abstract}

\section{INTRODUCTION}

Bioelectrical impedance analysis (BIA) is a popular technique for the assessment of body composition. In BIA, an imperceptible low voltage, low AC electrical current is applied to the body and the opposition to the flow of this electrical current, the impedance $(\mathrm{Z})$, is measured. The measured impedance is related to the total body water volume (TBW) according to the following relationship:

$V=\rho \frac{L^{2}}{Z}$

where $\mathrm{V}$ is the volume $(\mathrm{ml})$; $\mathrm{L}$ is the inter-electrode distance (cm), $\mathrm{Z}$ is the impedance (ohm) and $\rho$ is the resistivity coefficient (ohm.cm) of tissue fluid (for more detailed explanation the reader is referred to Cornish et al. [1], Thomas et al. [2] and Matthie [3]. In early BIA instruments, the drive current was fixed at a frequency of $50 \mathrm{kHz}$. This frequency approximates the characteristic frequency of lean tissue of the body where the majority of body water resides. Hence, when $\mathrm{Z}$ is measured at this frequency, it is a measure of total body water according to equation 1 . In order to use this relationship to predict TBW from measurements of whole body impedance, the value of the resistivity coefficient needs to be known. In practice, instead of using values for $\rho$ directly, the relationship between the impedance quotient $\left(\mathrm{L}^{2} / \mathrm{Z}\right)$ and volume is determined empirically by regression of the impedance quotient against TBW volume measured by an independent method. This relationship is then used as the prediction equation for TBW in all future studies. It should be recognised that impedance, $\mathrm{Z}$, is a vector quantity comprising the inherent resistance of tissue fluids $(\mathrm{R})$ and the opposition

*Address correspondence to this author at the School of Chemistry and Molecular Biosciences, The University of Queensland, St Lucia, Brisbane, QLD 4072, Australia; Tel: 6173365 4633; Fax: 6173365 4699;

E-mail: 1.ward@uq.edu.au to current flow due to cell membranes, the reactance $(\mathrm{Xc})$. Frequently, $\mathrm{R}$ is what is actually measured and substituted for $\mathrm{Z}$ in equation 1 .

Bioimpedance spectroscopy (BIS) is a variation on BIA in which current is applied over a range of frequencies, typically in a range of about 5 to $1000 \mathrm{kHz}$ [1-7]. BIS devices are phase-sensitive instruments, i.e., the phase shift that occurs as current flows through the body is measured as well as the impedance. Thus for each frequency of measurement, $\mathrm{Z}$, $\mathrm{R}$ and $\mathrm{Xc}$ may be determined. Data are analysed according to the Cole model [8] which assumes that the body can be modelled electrically as a resistor $\left(\mathrm{R}_{\mathrm{e}}\right)$ in parallel with a resistor $\left(\mathrm{R}_{\mathrm{i}}\right)$ and a capacitor $(\mathrm{Cm})$ representing the resistance of the extra-, intracellular resistances and membrane capacitance respectively. From the fit of the measured data to the model, typically achieved graphically $[1,7]$, the resistances at zero $\left(\mathrm{R}_{0}\right)$ and infinite $\left(\mathrm{R}_{\infty}\right)$ frequencies can be estimated. Theoretically, at zero frequency, current cannot penetrate cell membranes and thus, $\mathrm{R}_{0}$ is the resistance solely of extracellular water (ECW), i.e., $\mathrm{R}_{\mathrm{e}}$ [1]. Conversely, at infinite frequency, current readily passes across the cell membrane and, hence, $\mathrm{R}_{\infty}$ is the resistance of TBW. $\mathrm{R}_{\mathrm{i}}$, the resistance of intracellular water (ICW), can be calculated from the measured $\mathrm{R}_{0}$ and $\mathrm{R}_{\infty}$ by:

$$
R_{i}=\frac{\left(R_{o} x R_{\infty}\right)}{\left(R_{o}-R_{\infty}\right)}
$$

Hence, ECW, ICW and TBW water volumes can then be predicted from $R_{0}, R_{i}$ and $R_{\infty}$ respectively by equation 1 , where the impedance quotient becomes $\mathrm{L}^{2} / \mathrm{R}_{0}, \mathrm{~L}^{2} / \mathrm{R}_{\mathrm{i}}$ and $\mathrm{L}^{2} / \mathrm{R}_{\infty}$ respectively.

Typically, however, in BIS, rather than using such empirically-based prediction equations, body water volumes are predicted, using mixture theory $[5,9,10]$ from $\mathrm{R}_{0}$ and $\mathrm{R}_{\mathrm{i}}$. Mixture theory is based upon a model that describes the conductive properties of the body as a conductive medium (i.e., 
ECW) containing a volume of non-conductive material (i.e., membrane-bound cells) in suspension [9]. As with empirical equations, required input data are $\mathrm{R}_{0}, \mathrm{R}_{\mathrm{i}}$, height (as a surrogate for the inter-electrode distance, L) and resistivity coefficients for ECW and ICW for each sex. In addition, weight is required and values for body density $(\mathrm{Db})$ and a factor $(\mathrm{kb})$ to account for body proportions when using a wrist-ankle measurement geometry are incorporated.

Both BIA and BIS instruments are commercially available. Unfortunately, it has been observed that instruments from different manufacturers do not always provide identical results, particularly when used to measure the impedance of the human body, their intended purpose, compared to measurement of electrical circuit components [1, 11-15].

A recent study [16], designed to derive values for resistivity coefficients $(\rho)$ for control subjects, provided the opportunity to compare the three commercially available BIS instruments: the BIS 4200 Hydra (Xitron Technologies, San Diego, USA); the BIS SFB7 (ImpediMed Ltd., Brisbane, Australia) and the older model BIS SFB3 (UniQuest-SEAC, Brisbane, Australia). Many independent studies of body composition using all three analysers have been published $[17,18]$ but few inter-instrument comparisons have been performed and have been largely limited to electrical testing using simulation circuits $[12,14,15]$. This report presents the results of an inter-machine comparison using both measurements of a component circuit artefact and measurements in humans.

\section{MATERIALS AND METHODS}

\section{Subjects}

The study was an analysis of data drawn from a database of impedance data collected from control subjects, generally recruited from staff and students of the University of Queensland, as part of an ongoing study designed to determine resistivity coefficients in healthy normal subjects. The study received ethical approval from the University of Queensland Medical Research Ethics Committee and written informed consent was obtained from all subjects. Subjects were a sub-group of participants in this study in which impedance data was available for each of the impedance instruments and comprised 25 males and 25 females. The characteristics of the subjects are presented in Table $\mathbf{1 .}$

\section{Impedance Measurements}

\section{Instruments and Calibration}

Impedance measurements were performed using a Hydra 4200, SFB3 and SFB7 impedance analysers. All instruments were used according to the respective manufacturers' instructions. The Hydra 4200 and SFB7 are calibrated by the manufacturer and there is no facility for user calibration. The SFB3 is provided with a series of calibration resistors and a resistor-resistor plus capacitor (RRC) circuit for calibration and the instrument was calibrated in accordance with the manufacturer's instructions as described elsewhere [5].

\section{Circuit Measurements}

An RRC circuit (604 ohm - $402 \mathrm{ohm} \mathrm{-} 1 \mathrm{nF}$ ) was used to check instrument calibration for quality control purposes prior to each measurement session. These occurred on 10 separate occasions on over a 13-month period, Measurements were made in triplicate on each occasion.

\section{Human Measurements}

Whole body, wrist to ankle, impedance was determined on the right side of the body according to procedures described previously $[19,20]$ and commonly adopted for impedance measurements in humans $[17,18]$. Briefly, subjects were asked to lie supine on a non-conductive examination couch arms at their sides and legs slightly straight and slightly abducted. Subjects were dressed in light indoor clothing without shoes and socks and with jewellery removed. Sites of attachment of EKG-style gel electrodes (ImpediMed, Brisbane, Australia) were cleaned with alcohol wipes prior to electrode attachment. Electrode sites were: current drive electrodes at the base of the toes and fingers and voltage sense electrodes on the dorsal surface of the wrist and ankle between centrally between the malleoli.

The order in which instruments were used was random. Measurement time varied between approximately $1 \mathrm{~s}$ for the SFB7 and $10 \mathrm{~s}$ for the SFB3 and Hydra. Consecutive triplicate measurements were obtained with the Hydra and SFB7 instruments and single measurements only with the SFB3, necessitated by the limited memory capacity of this instrument. Immediately following measurement with an instrument, its leads were unclipped from the electrodes and the leads of the next instrument attached. This procedure was then repeated with the third instrument and all measurements were concluded within a $10-$ min period.

Reproducibility of measurement was assessed in a subgroup of ten subjects, each measured three times in a single measurement session with both the SFB7 and Hydra instruments.

\section{Data Analysis}

Data from each instrument were uploaded to a PC for analysis. The SFB3 provides an ASCII text file listing of impedance and phase angle, from which $\mathrm{R}$ and Xc were calculated, at each frequency of measurement, using the relationship $\mathrm{Z}^{2}=\mathrm{R}^{2}+\mathrm{Xc}^{2}$. Both the SFB7 and Hydra 4200 provide, again as ASCII files, listings of $\mathrm{R}$ and $\mathrm{Xc}$ at each frequency of measurement. These frequency-resistance-reactance files for each instrument provided a common data input format for further analysis, Conventionally such data are fitted to the Cole model by regression of Xc versus $\mathrm{R}$, depicted graphically as a semi-circular plot $[1,6,7,13,20]$, with $\mathrm{R}_{0}$ and $\mathrm{R}_{\infty}$ determined by extrapolation.

The fat-free masses (FFM) of the human subjects was predicted from the SFB7 and Hydra data using mixture theory as described above. Resistivity coefficients for ECW and ICW have been derived using both the SFB7 [16] and Hydra 4200 instruments [5] but not, to the author's knowledge, for the SFB3. FFM was predicted from the SFB7 and Hydra 4200 impedance data using all combinations of data and resistivity coefficients. All other required data were maintained constant, viz, $\mathrm{Db}=1.05 \mathrm{~g} / \mathrm{ml}, \mathrm{kb}=4.3$ and a hydration factor (TBW:FFM) of $0.732 \mathrm{ml} / \mathrm{g}$.

All analyses were performed using Bioimp software (version 4.5.0 2005, ImpediMed Ltd., Brisbane, Australia). In order to provide a consistent data analysis procedure for each 
Table 1. Characteristics of Subjects Used for the Assessment of Body Composition by Bioimpedance Spectroscopy. Data Presented as mean \pm SD (Range)

\begin{tabular}{|c|c|c|}
\hline \multirow[t]{2}{*}{ Parameter } & \multicolumn{2}{|c|}{ Sex } \\
\hline & Male & Female \\
\hline Age (y) & $\begin{array}{c}36.3 \pm 14.5 \\
(18.7-63.2)\end{array}$ & $\begin{array}{c}29.2 \pm 7.1 \\
(21.0-52.5)\end{array}$ \\
\hline Height (cm) & $\begin{array}{c}178.5 \pm 5,5 \\
(168.5-190.1)\end{array}$ & $\begin{array}{c}166.1 \pm 7.1 \\
(154.1-183.5)\end{array}$ \\
\hline Body mass index $\left(\mathrm{kg} / \mathrm{m}^{2}\right)$ & $\begin{array}{c}24.7 \pm 3.0 \\
(20.0-32.5)\end{array}$ & $\begin{array}{c}21.6 \pm 1.9 \\
(17.8-25.2)\end{array}$ \\
\hline
\end{tabular}

Table 2. Precision and Accuracy of Measurement of Impedance of a Test Resistor-Resistor + Capacitor (RRC) circuit simulating a Cole Model

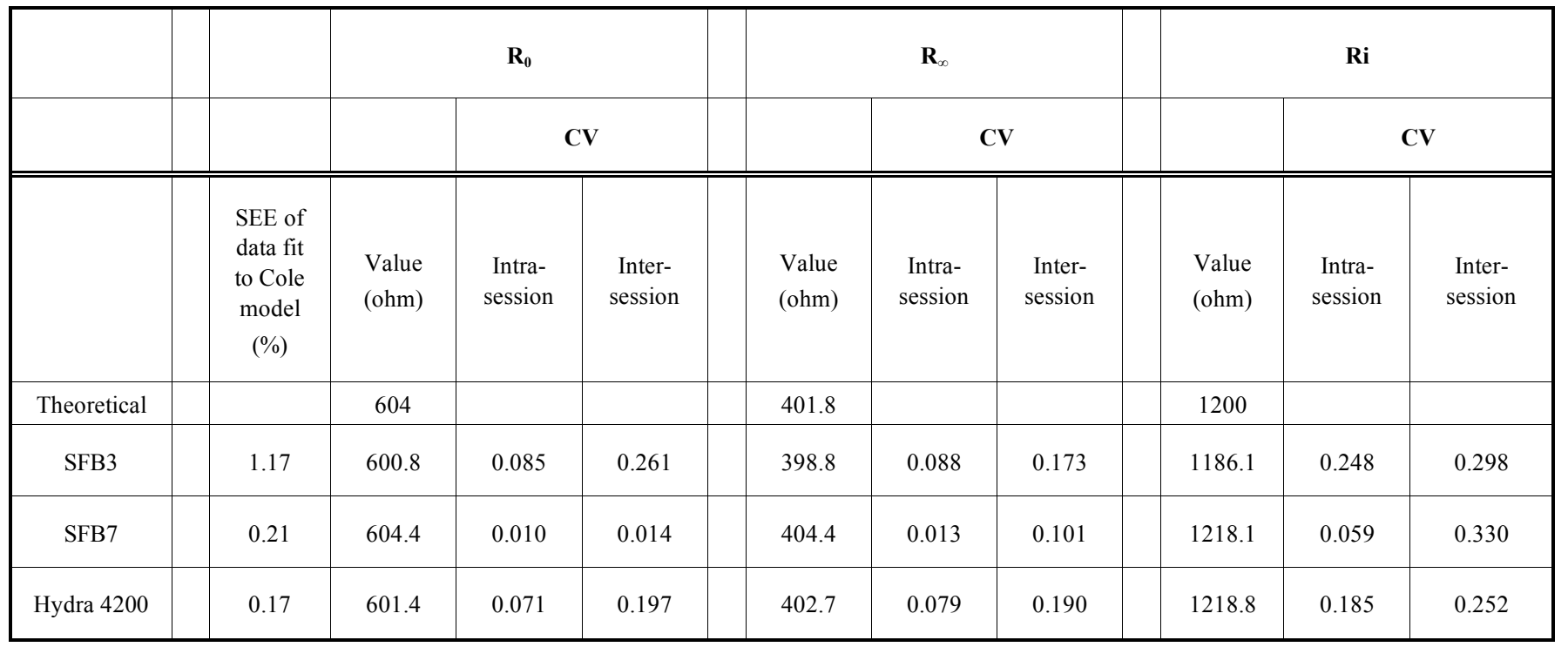

data set for each instrument, the software default settings (frequency range 10 to $500 \mathrm{kHz}$, no noise rejection, Td correction applied) were used for all analyses.

\section{Statistical Analysis}

Data are presented, where appropriate, as means \pm standard deviation (SD). Comparison of group data, where appropriate, was performed by paired $t$-test [21]. Agreement between the methods, for the measurement of fat-free and fat mass, was performed by concordance correlation analysis $[21,22]$ and the limits of agreement procedure [23]. Statistical significance was set at $P<0.05$. Statistical analysis was performed was performed using MedCalc (version 9.6.4.0, Gent, Belgium).

\section{RESULTS}

Anthropometric characteristics of the subjects are presented in Table 1. The subjects were a random cross-section of the population and although no attempt was made to match the genders for characteristics, they were generally similar. As expected, the males were taller and heavier and slightly older. The mean body mass index of each group was within the normal weight range $\left(20-24.9 \mathrm{~kg} / \mathrm{m}^{2}\right)$ although the males included some subjects in the obese range $(>30$ $\mathrm{kg} / \mathrm{m}^{2}$ ).

All three instruments provided impedance data for the test circuit that were well fitted to the Cole model (Table 2). The Bioimp software provides an estimate of the goodness of fit (\% standard error of the estimate) and this was $<0.3 \%$ for the SFB7 and Hydra 4200 instruments and slightly over $1 \%(1.17 \%)$ for the older model SFB3. The coefficients of variation for replicate measurements were excellent $(<0.5 \%)$ for all instruments. CVs were generally smaller for replicate measurements within a single measurement session than between measurement sessions but all instruments remained within calibration over the 13-month test period. Reproduci- 
Table 3. Reproducibility of Measurement of Impedance for 10 Subjects

\begin{tabular}{|c|c|c|c|c|}
\hline & $\begin{array}{c}\text { SEE of data fit to Cole } \\
\text { model } \\
(\% \pm \mathrm{SD})\end{array}$ & $\mathrm{R}_{0}$ & $\mathrm{R}_{\infty}$ & $\mathrm{R}_{\mathrm{i}}$ \\
\hline SFB7 & $0.661 \pm 0.051$ & 0.152 & 0.321 & 0.877 \\
\hline Hydra 4200 & $0.256 \pm 0.028$ & 0.117 & 0.123 & 0.442 \\
\hline
\end{tabular}

${ }^{1}$ Mean coefficient of variation for three measurements per subject.

bility was slightly worse for $\mathrm{R}_{\mathrm{i}}$ than for $\mathrm{R}_{0}$ and $\mathrm{R}_{\infty}$, as observed previously [6] reflecting propagation of error as this value is calculated from the estimated $R_{0}$ and $R_{\infty}$ values. Accuracy of determination of $\mathrm{R}_{0}$ and $\mathrm{R}_{\infty}$ was very good, all instruments being within $0.5 \%$ of the component value $(0.1 \%$ precision components were used). Accuracy of measurement of $\mathrm{R}_{\mathrm{i}}$ was less good but was still within $1.6 \%$ of the theoretical value, again reflecting propagation of error in the determination of this value.

Reproducibility of measurement for human subjects was generally poorer than that observed for test circuits. Data exhibited a greater degree of noise such that the standard error of the fit of the data to the Cole model was approxi- mately 2-fold greater than that for the test circuit but was, nevertheless, was less than 1\% for both the SFB7 and Hydra instruments (Table 3). Correspondingly, the coefficients of variation for determination of $R_{0}, R_{\infty}$ and $R_{i}$ were greater than observed for the test circuit but again were all less than $1 \%$ (Table 3 ).

Comparisons between the three analysers for the measurement of impedance parameters in the human subjects are presented in Table 4. All three analysers provided data that were highly and significantly correlated $\left(r_{c}=0.839\right.$ to 0.997 , $P<0.0001$ ) for $\mathrm{R}_{0}$ and $\mathrm{R}_{\infty}$, Table 1 and Fig. 1). Correlations between the SFB7 and SFB3 instruments when measuring $\mathrm{R}_{\mathrm{i}}$ were also good ( $r_{c}=0.894$ to 0.990$)$ but were poor between

Table 4. Correlation and Limits of Agreement between BIS instruments for Measurement of Whole Body $R_{0}, R_{\infty}$ and $R_{i}$ in $H u m a n s$

\begin{tabular}{|c|c|c|c|c|c|c|c|c|c|c|}
\hline Comparison & \multicolumn{5}{|c|}{ Male } & \multicolumn{5}{|c|}{ Female } \\
\hline & \multicolumn{10}{|c|}{$\mathrm{R}_{0}$} \\
\hline $\begin{array}{l}\text { SFB7 v } \\
\text { SFB3 }\end{array}$ & 0.997 & 4.1 & $\begin{array}{c}1.9 \\
(0.3 \%)\end{array}$ & $\begin{array}{l}-6.1 \text { to } 10.0 \\
(-1.0 \text { to } 1.7 \%)\end{array}$ & 0.023 & 0.997 & 5.2 & $\begin{array}{c}0.7 \\
(0.1 \%)\end{array}$ & $\begin{array}{c}-9.3 \text { to } 10.7 \\
(-1.3 \text { to } 1.5 \%)\end{array}$ & 0.0521 \\
\hline $\begin{array}{l}\text { SFB3 v } \\
\text { Hydra }\end{array}$ & 0.962 & 9.6 & $\begin{array}{c}-14.3 \\
(-2.4 \%)\end{array}$ & $\begin{array}{c}-33.8 \text { to } 5.2 \\
(-5.7 \text { to } 0.9 \%)\end{array}$ & 0.0001 & 0.971 & 6.0 & $\begin{array}{c}-16.5 \\
(-2.4 \%)\end{array}$ & $\begin{array}{l}-28.0 \text { to }-4.9 \\
(-4.1 \text { to } 0.7 \%)\end{array}$ & 0.0001 \\
\hline $\begin{array}{l}\text { SFB7 v Hy- } \\
\text { dra }\end{array}$ & 0.968 & 10.0 & $\begin{array}{c}-12.3 \\
(-2.1 \%)\end{array}$ & $\begin{array}{c}-32.0 \text { to } 7.3 \\
(-5.4 \text { to } 1.2 \%)\end{array}$ & 0.0001 & 0.974 & 5.0 & $\begin{array}{l}-15.8 \\
(-2.3 \%)\end{array}$ & $\begin{array}{c}-25.5 \text { to }-6.1 \\
(-3.7 \text { to }-0.9 \%)\end{array}$ & 0.0001 \\
\hline $\begin{array}{l}\text { SFB7 v } \\
\text { SFB3 }\end{array}$ & 0.971 & 6.6 & $\begin{array}{c}10.8 \\
(2.7 \%)\end{array}$ & $\begin{array}{c}-1.9 \text { to } 23.6 \\
(-0.5 \text { to } 5.8 \%)\end{array}$ & 0.0001 & 0.997 & 3.2 & $\begin{array}{c}2.3 \\
(0.5 \%)\end{array}$ & $\begin{array}{c}-5.0 \text { to } 9.7 \\
(-1.0 \text { to } 1.9 \%)\end{array}$ & 0.005 \\
\hline $\begin{array}{l}\text { SFB3 v } \\
\text { Hydra }\end{array}$ & 0.955 & 5.9 & $\begin{array}{c}13.4 \\
(3.4 \%)\end{array}$ & $\begin{array}{c}-0.8 \text { to } 27.5 \\
(-0.2 \text { to } 7.0 \%)\end{array}$ & 0.0001 & 0.857 & 5.9 & $\begin{array}{c}31.1 \\
(6.3 \%)\end{array}$ & $\begin{array}{l}11.5 \text { to } 50.7 \\
2.3 \text { to } 10.3\end{array}$ & 0.0001 \\
\hline $\begin{array}{c}\text { SFB7 v Hy- } \\
\text { dra }\end{array}$ & 0.886 & 5.5 & $\begin{array}{l}24.2 \\
(6.0)\end{array}$ & $\begin{array}{l}11.0 \text { to } 37.4 \\
(2.7 \text { to } 9.2 \%)\end{array}$ & 0.0001 & 0.839 & 5.7 & $\begin{array}{c}33.5 \\
(6.8 \%)\end{array}$ & $\begin{array}{c}17.3 \text { to } 49.6 \\
(3.5 \text { to } 10.0 \%)\end{array}$ & 0.0001 \\
\hline
\end{tabular}


Table 4. Contd...

\begin{tabular}{|c|c|c|c|c|c|c|c|c|c|c|}
\hline Comparison & \multicolumn{5}{|c|}{ Male } & \multicolumn{5}{|c|}{ Female } \\
\hline & \multicolumn{10}{|c|}{$\mathrm{Ri}$} \\
\hline $\begin{array}{l}\text { SFB7 v } \\
\text { SFB3 }\end{array}$ & 0.894 & 61.27 & $\begin{array}{c}94.6 \\
(7.3 \%)\end{array}$ & $\begin{array}{c}-26.3 \text { to } \\
215.4 \\
(-2.0 \text { to } \\
16.7 \%)\end{array}$ & 0.002 & 0.990 & 42.0 & $\begin{array}{c}22.1 \\
(1.3 \%)\end{array}$ & $\begin{array}{c}-67.7 \text { to } \\
111.9 \\
(-3.8 \text { to } \\
6.3 \%)\end{array}$ & 0.022 \\
\hline $\begin{array}{l}\text { SFB3 v } \\
\text { Hydra }\end{array}$ & 0.682 & 56.9 & $\begin{array}{c}167.2 \\
(14.0 \%)\end{array}$ & $\begin{array}{c}-5.0 \text { to } 339.5 \\
(-0.4 \text { to } \\
28.3 \%)\end{array}$ & 0.0001 & 0.390 & 87.0 & $\begin{array}{c}426.9 \\
(24.5 \%)\end{array}$ & $\begin{array}{c}52.0 \text { to } 801.6 \\
(3.0 \text { to } \\
46.0 \%)\end{array}$ & 0.0001 \\
\hline
\end{tabular}

${ }^{1}$ Concordance correlation; ${ }^{2}$ standard error of the estimate of regression; ${ }^{3}$ statistical significance of paired comparison.
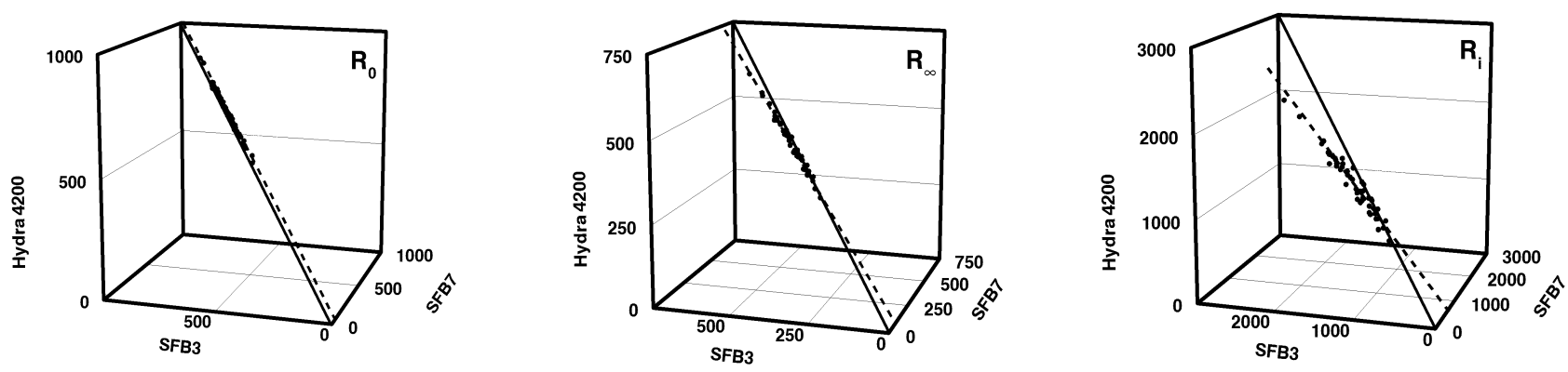

Fig. (1). Plot of agreement between three different impedance analysers for the measurement of $R_{0}, R_{\infty}$ and $R_{i}$.

$\begin{array}{llll}\text { Top panel } & \mathrm{R}_{0} & \text { Legend } & \\ \text { Middle panel } & \mathrm{R}_{\infty} & \bullet & \text { Data points } \\ \text { Bottom panel } & \mathrm{R}_{\mathrm{i}} & - & \text { Line of identity } \\ & & --- & \text { Best-fit line for data }\end{array}$

either of these two instruments and the Hydra $4200\left(r_{c}=\right.$ 0.390 to 0.682 ). Despite these strong correlations the instruments were not always in agreement. The biases and limits of agreement were good between all analysers when measuring $R_{0}$ and $R_{\infty}$, being generally less than $5 \%$ and $6 \%$ respectively. Agreement was much poorer for $\mathrm{R}_{\mathrm{i}}$, particularly for comparisons between the SFB3 or SFB7 and the Hydra 4200. In all cases, however, the differences were significant $(P<0.05$ to 0.0001$)$ upon pair-wise testing.

BIS analysers, unlike impedance circuit analysers, are designed for the assessment of body composition. It is possible that, despite the differences observed for the measured impedances between analysers, these differences are accounted for by instrument-specific resistivity coefficients when predicting body composition. Comparisons of fat-free masses predicted from the impedance data for each analyser are presented in Fig. (2) and the statistical analyses of these data in Table 5. As observed for the measured impedances, all three instruments produce predictions that are highly correlated with generally good agreement. Most notably, the closest agreement was achieved for comparisons between analysers when data obtained with a specific analyser were analysed using coefficients specific for that analyser, e.g., SFB7 versus Hydra 4200 yielded a bias of $3.3 \%$ with limits of agreement of $\pm 6.7 \%$ (Table 5 , comparison 3 ).

\section{DISCUSSION}

The determination of human body composition in vivo is difficult [24]. The methods used should be accurate, precise and reliable yet as minimally invasive as possible, ideally totally non-invasive, easily used and inexpensive. BIS techniques, and BIA methods in general, certainly fulfil these latter requirements but questions have been raised over the validity of the former. Previous studies have generally found that impedance analysers used in human body composition research are generally highly precise and repeatable but of 


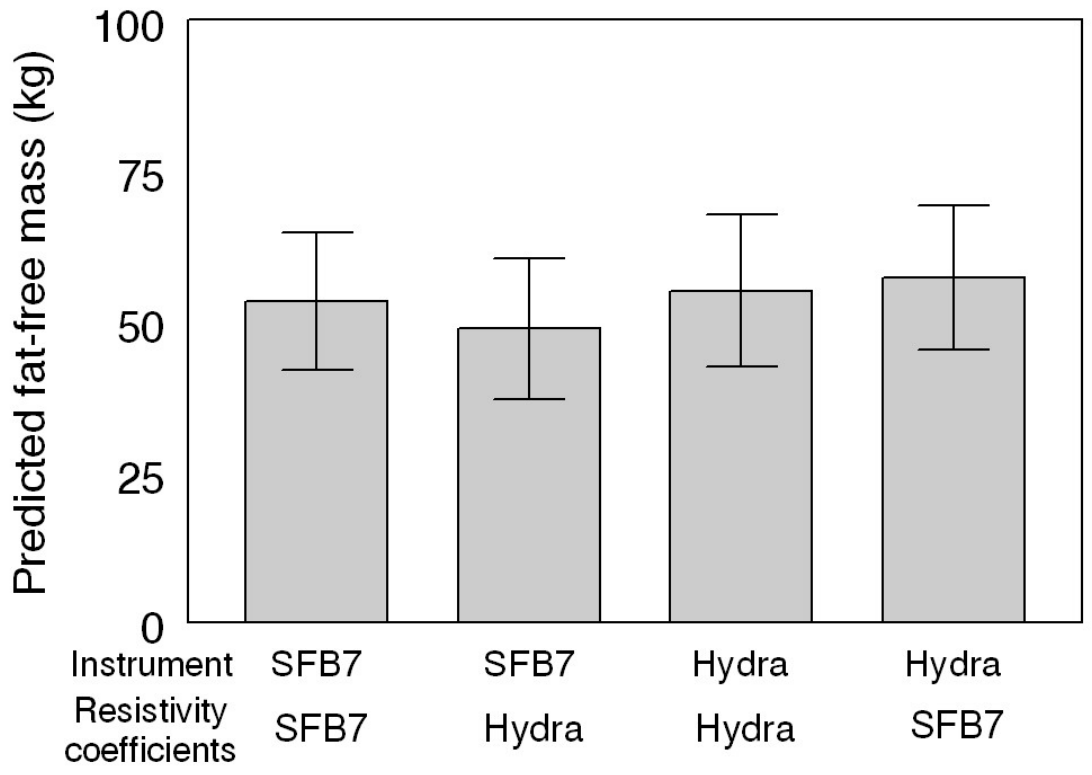

\section{Instrument-resistivity coefficient combination}

Fig. (2). Plot of fat-free masses for all subjects predicted by different combinations of instrument and resistivity coefficients used in the prediction model. Data are presented as means \pm standard deviation. For statistical comparison of the data see Table 5.

Table 5. Comparison of Fat-Free Masses Predicted by Bioimpedance Spectroscopy for Different Combinations of Instruments and Resistivity Coefficients. Pooled Data for All Subjects

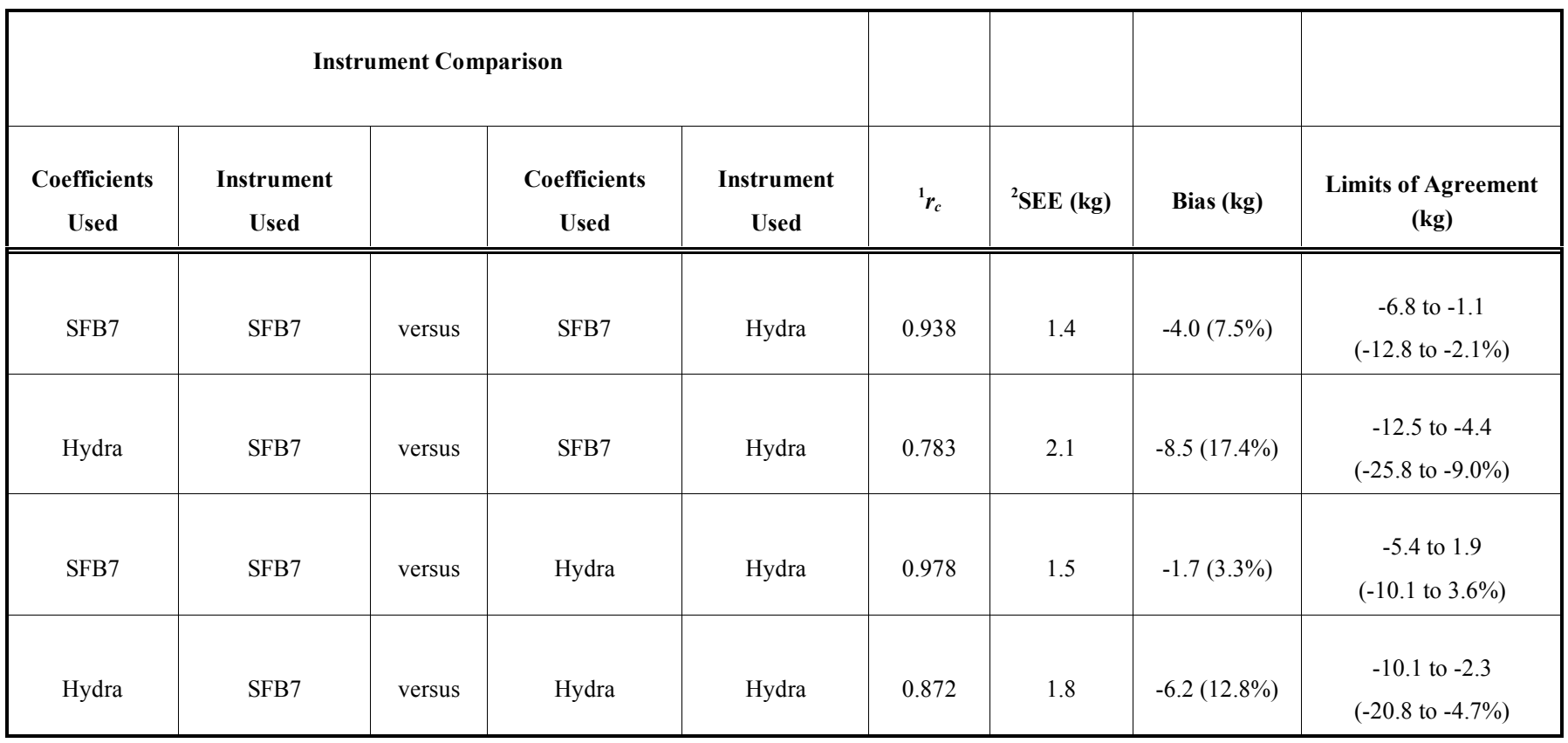

${ }^{1}$ Concordance correlation; ${ }^{2}$ standard error of the estimate of the correlation

questionable accuracy when compared to reference methods such as multi-compartment models or tracer dilution [25, 26]. In addition, the technical performance of impedance analysers has been questioned [14] and new instrument designs continue to appear e.g., [27]. In particular, the ability of bioimpedance spectrometers to measure impedances accurately at high frequencies has been of concern $[13,15]$. Surprisingly however, there appears to have been no systematic attempt to compare commercially available analysers with regard to the degree to which they provide data that agree or are interchangeable. The present study aimed to fulfil this need.

It is clear from the data presented here that all three analysers perform creditably when measuring electronic circuits. It could be argued from engineering principles, that this is the only true test of instrument accuracy and precision. BIS 
analysers are designed to measure an electrical property, impedance or its derivatives, resistance and reactance, and in this regard they were all found to be highly precise and reproducible and accurate to within $0.5 \%$ when tested on test circuits of known impedance values. Reproducibility was slightly worse when measuring human subjects but coefficients of variation were still less than $1 \%$. These performance figures, obtained for the current model instruments, SFB7 and Hydra only, are slightly better than those reported previously for the older SFB3 instrument [6]. Not surprisingly, instrument performance was also slightly worse when estimating impedance parameters that can not be measured directly. It is important, however, to recognise the principle of "fit for intended purpose". Under most commercial law, goods and services should be fit for or fulfil the purpose for which they were purchased. With respect to BIS analysers, this is the prediction of body composition. All three analysers provided similar but not identical estimates of FFM when tested in humans under typical measurement conditions. The magnitude of the difference between instruments varied depending upon which pair of instruments was being compared, the smallest mean difference being only $3.3 \%$ for the two BIS instruments in current production, namely the SFB7 and Hydra 4200. The limit of agreement between these two instruments was approximately $\pm 7 \%$.

It is appropriate to question whether this difference is clinically important. In absolute terms, the bias was $-1.7 \mathrm{~kg}$ (SFB7-Hydra 4200) with a standard deviation of $1.8 \mathrm{~kg}$ and a standard error of $0.26 \mathrm{~kg}$. The corresponding $t$ value for 49 degrees of freedom is 2.01 . The $95 \%$ confidence interval for the bias is therefore $-1.7 \pm 2.01 \times 0.26=-2.27$ to $-1.19 \mathrm{~kg}$. Thus the potential bias between these instruments could be as much as $2.3 \mathrm{~kg}$. It is instructive to compare this to errors in determination of FFM from measurement of body density, an accepted reference method, of between 1.5 and $1.9 \mathrm{~kg}$ [28].

It is important to recognise that the data presented here provide no information about the inherent accuracy of the BIS technique for the measurement of body composition. Although the data show that the different instruments perform similarly, they may all be equally accurate or inaccurate when predicting body composition compared to accepted reference methods such as multi-compartment models or tracer dilution. Many validation studies of BIS against these reference techniques have been performed $[3,4,17,18$, 29] but it is generally accepted that overall error is of the order of 2 to $4 \mathrm{~kg}$ FFM. The sources of the errors are various and include, technical errors of measurement associated with the equipment, inappropriate or non-standardised measurement protocols, errors in data analysis and inadequacies in the predictive algorithms. The present data suggests that technical performance of BIS analysers is very good and, since, the measurement protocol was standardised for all analysers, this implies that the major sources of error when predicting body composition are data analysis and prediction. In the present study, an identical data analytical technique was used for all data irrespective of analyser used for measurement yet differences of up to $8.5 \mathrm{~kg}$ in the prediction of FFM were observed between different combinations of instrument and resistivity coefficients in the predictive algorithm. That this difference could be reduced to as little as 1.7 kg by appropriate choice of resistivity coefficients highlights the importance of method standardisation and the need to ensure that coefficients used for prediction are specific to the analyser being used.

\section{CONCLUSIONS}

In conclusion, the currently available BIS analysers are suitable for their intended purpose of measuring the impedance of the human body. It should be recognised that while they perform similarly, they do not provide identical data. Inter-instrument differences can be minimised by standardisation of measurement protocol, adoption of common data analytical methods and, where appropriate, instrumentspecific resistivity coefficients. Under such circumstances, inter-instrument differences approximate $2 \mathrm{~kg}$ when predicting fat-free mass.

\section{ACKNOWLEDGEMENTS}

The technical assistance of J. Dyer, S. van Rosendal and $\mathrm{K}$. Sharpe in collecting BIS data is gratefully acknowledged. The University of Queensland and ImpediMed Ltd. are gratefully acknowledged for providing partial financial support for the original studies which contributed to the database from which the data used here were obtained.

\section{STATEMENT OF CONFLICT OF INTEREST:}

Author Ward has consulted to Impedimed Ltd. Impedimed Ltd., while providing partial financial support for original data collection, had no involvement in the conception and execution of the study, data analysis or in the preparation of the manuscript.

\section{AUTHORS' CONTRIBUTION:}

Ward conceived the study, supervised data collection, undertook data analysis and manuscript preparation.

\section{REFERENCES}

[1] Cornish BH, Thomas BJ, Ward LC. Improved prediction of extracellular and total body water using impedance loci generated by multiple frequency bioelectrical impedance analysis. Phys Med Biol 1993; 38: 337-46.

[2] Thomas BJ, Ward LC, Cornish BH. Bioimpedance spectrometry in the determination of body water compartments: accuracy and clinical significance. Appl Radiat Isotop 1998; 49: 447-55.

[3] Matthie JR. Bioimpedance measurements of human body composition: critical analysis and outlook. Expert Rev Med Devices 2008; 5: 239-61.

[4] Jaffrin MY, Morel H. Body fluid volumes measurements by impedance: a review of bioimpedance spectroscopy (BIS) and bioimpedance analysis (BIA) methods. Med Eng Phys 2008; 30: 125769.

[5] De Lorenzo A, Andreoli A, Matthie J, Withers P. Predicting body cell mass with bioimpedance by using theoretical methods: a technological review. J Appl Phys 1997; 82: 1542-58.

[6] Ward LC, Byrne NM, Rutter K, et al. Reliability of multiple frequency bioelectrical impedance analysis: an intermachine comparison. Am J Hum Biol 1997; 9: 63-72.

[7] Ward LC, Cornish BH. Data analysis in multiple frequency bioelectrical impedance analysis. Physiol Meas 1998; 19: 275-283.

[8] Cole KS. Electric impedance of suspensions of spheres. J Gen Physiol 1928; 12: 29-36.

[9] Hanai T. In: Sherman PH, Ed. Emulsion Science. London: Academic Press 1968; 354-477.

[10] Ward LC, Elia M, Cornish BH. Potential errors in the application of mixture theory to multifrequency bioelectrical impedance analysis. Physiol Meas 1998; 19: 53-60. 
[11] Smye SW, Sutcliffe J, Pitt E. A comparison of four commercial systems used to measure whole-body electrical impedance. Physiol Meas 1993; 14: 473-8.

[12] Smith DN. Comments on 'A comparison of four commercial systems used to measure whole-body electrical impedance'. Physiol Meas 1994; 15: 231-4.

[13] Stroud DB, Cornish BH, Thomas BJ, Ward LC. The use of ColeCole plots to compare two multifrequency bioimpedance instruments. Clin Nutr 1995; 14: 307-11.

[14] Oldham NM. Overview of bioelectrical impedance analysers. Am J Clin Nutr 1996; 64: 405S-12S.

[15] Bolton M, Ward LC, Khan A, et al. Sources of error in bioimpedance spectroscopy. Physiol Meas 1998; 19: 235-44.

[16] Ward LC, Isenring E, Dyer J, Battersby K, Bengston J, Kagawa M. Constancy of resistivity coefficients for bioimpedance spectroscopy (BIS). Int J Body Comp Res 2008; 6: 63.

[17] Kyle UG, Bosaeus I, De Lorenzo AD, et al. Bioelectrical impedance analysis-part I: review of principles and methods. Clin Nutr 2004; 23: 1226-43.

[18] Kyle UG, Bosaeus I, De Lorenzo AD, et al. Bioelectrical impedance analysis-part II: utilization in clinical practice. Clin Nutr 2004; 23: $1440-53$

[19] Cornish BH, Ward LC, Thomas BJ, Jebb SA, Elia, M. Evaluation of body water volumes in humans by multiple frequency bioelectrical impedance analysis (MFBIA). Eur J Clin Nutr 1996; 50: 15964

[20] Ward LC, Cornish BH, Paton NIJ, Thomas BJ. Multiple frequency bioelectrical impedance analysis: a cross-validation study of the in- ductor circuit and Cole-Cole models. Physiol Meas 1999; 20: 33347.

[21] Zar JH. Biostatistical analysis. 4th ed. Upper Saddle River: Prentice Hall 1999.

[22] Lin LI. A concordance correlation coefficient to evaluate reproducibility. Biometrics 1989; 45: 255-68.

[23] Bland JM, Altman DO. Statistical methods for assessing agreement between two methods of clinical measurement. Lancet 1986; 1: 307-10.

[24] Roche AF, Heymsfield SB, Lohman TG, Eds. Human Body Composition. Champaign: Human Kinetics Press 1996.

[25] Cox-Reijven P, van Kreel B, Soeters PB. Accuracy of bioelectrical impedance spectroscopy in measuring changes in body composition during severe weight loss. J Parenter Enteral Nutr 2002; 26: 120-27.

[26] Chertow GM. With bioimpedance spectroscopy, the errors get fat when the patients get slim. J Parenter Enteral Nutr 2002; 26:128-9.

[27] Aroom K, Harting M, Cox Jr C, Radharkrishnan R, Smith C, Gill B. Bioimpedance analysis: A guide to simple design and implementation. J Surg Res 2009; 153: 23-30.

[28] Roche AF. In: Roche AF, Heymsfield SB, Lohman TG. Eds. Human Body Composition. Champaign: Human Kinetics Press 1996; 167-89.

[29] Earthman C, Traughber D, Dobratz J, Howell W. Bioimpedance spectroscopy for clinical assessment of fluid distribution and body cell mass. Nutr Clin Pract 2007; 22: 389-405.

(C) L.C. Ward; Licensee Bentham Open.

This is an open access article licensed under the terms of the Creative Commons Attribution Non-Commercial License (http://creativecommons.org/licenses/by-nc/3.0/) which permits unrestricted, non-commercial use, distribution and reproduction in any medium, provided the work is properly cited. 